\title{
Evaluation of Use of Epstein-Barr Viral Load in Patients after Allogeneic Stem Cell Transplantation To Diagnose and Monitor Posttransplant Lymphoproliferative Disease
}

\author{
Barbara C. Gärtner, ${ }^{1}$ Hansjörg Schäfer, ${ }^{2}$ Katja Marggraff, ${ }^{1}$ Günter Eisele, ${ }^{1}$ Marco Schäfer, ${ }^{1}$ \\ Klaus Roemer, ${ }^{1}$ Hans-Jürgen Laws, ${ }^{3}$ Martina Sester, ${ }^{4}$ Urban Sester, ${ }^{4}$ \\ Hermann Einsele, ${ }^{2}$ and Nikolaus Mueller-Lantzsch ${ }^{1 *}$ \\ Department of Virology ${ }^{1}$ and Department of Internal Medicine, ${ }^{4}$ University of Homburg/Saar, Homburg/Saar, \\ Department of Internal Medicine, University of Tübingen, Tübingen, ${ }^{2}$ and Department of \\ Pediatrics, University of Düsseldorf, Düsseldorf, ${ }^{3}$ Germany
}

Received 14 August 2001/Returned for modification 22 September 2001/Accepted 10 November 2001

\begin{abstract}
Epstein-Barr virus (EBV)-induced posttransplant lymphoproliferative disease (PTLD) continues to be a serious complication following transplantation. The aim of the present study was to evaluate the EBV load as a parameter for the prediction and monitoring of PTLD. The EBV load was analyzed by a quantitative competitive PCR with 417 whole-blood samples of 59 patients after allogeneic stem cell transplantation (SCT). The EBV load was positive for all 9 patients with PTLD and for 17 patients without PTLD. The viral loads of patients with manifest PTLD differed from the loads of those without PTLD (median loads, $1.4 \times 10^{6}$ versus $4 \times 10^{4}$ copies/ $\mu \mathrm{g}$ of DNA; $P<\mathbf{0 . 0 0 0 1}$ ). A threshold value of $10^{5}$ copies/ $\mu \mathrm{g}$ of DNA showed the best diagnostic efficacy (sensitivity, 87\%; specificity, 91\%). However, in patients with less than three major risk factors for PTLD, the positive predictive value of this threshold was rather low. One week prior to the manifestation of PTLD, the EBV load was as low in patients who developed PTLD as in patients without disease (median, 2.2 $\times 10^{4}$ copies/ $\mu \mathrm{g}$ of DNA; $P$ was not significant). EBV DNA tested positive first at 20 to 71 days prior to the clinical manifestation of PTLD and occurred with the same delay after transplantation regardless of disease (median delay, 52 versus 63 days; $P$ was not significant). EBV DNA was detected earlier in patients with primary infections than in those with reactivations (33 versus 79 days; $P=0.01$ ), but the peak levels were similar in the two groups. EBV primary infection or EBV reactivation is frequent in patients after allogeneic SCT but results in PTLD only in a subgroup of patients. Although evaluation of the EBV load has limitations, the EBV load represents a valuable parameter to guide therapy.
\end{abstract}

Epstein-Barr virus (EBV) causes a mild self-limiting disease during primary infection and persists for life in latently infected B cells. These cells may outgrow as immortal lymphoblastoid cell lines in vitro but are controlled by a strong immune response in vivo, mediated mostly through cytotoxic $\mathrm{T}$ cells. However, in immunosuppressed individuals, EBV-infected B lymphocytes may proliferate rapidly, resulting in polyclonal or monoclonal lymphoproliferative disease $(2,14,22,24$, 35). This posttransplant lymphoproliferative disease (PTLD) remains a significant cause of morbidity and mortality in transplant recipients.

In stem cell transplantation (SCT) recipients, PTLD is observed mainly during the first 6 months after transplantation. The incidence of PTLD after transplantation varies considerably depending on the major risk factors such as EBV primary infection after transplantation, the use of antithymocyte globulin or anti-CD3 monoclonal antibodies during immunosuppressive therapy, or cytomegalovirus (CMV) primary infection or reactivation $(3,18,37)$. Furthermore, mismatched or unrelated stem cell grafts or T-cell-depleted grafts are associated with an increased risk for PTLD. Although the incidence of PTLD after allogeneic SCT is as low as $0.5 \%$ in patients with-

\footnotetext{
* Corresponding author. Mailing address: Department of Virology, Bldg. 47, University of Saarland Medical School, D-66421 Homburg/ Saar, Germany. Phone: 49-6841-163932. Fax: 49-6841-163980. E-mail: vinmue@med-rz.uni-sb.de.
}

out major risk factors, it may rise to $22 \%$ in patients with three or more risk factors (3).

Despite the availability of therapeutic options including the reduction of immunosuppression, the use of anti-CD20 antibody (Rituximab), adoptive T-cell transfer, or aggressive chemotherapy, PTLD is still associated with a high rate of mortality $(11,15,25,28,34)$. Thus, prevention of PTLD is a major goal. Reduction of immunosuppression or adoptive T-cell transfer has yielded encouraging results as prophylaxis for PTLD (29). However, as shown for CMV, preemptive therapy of patients at risk seems to be superior to a prophylactic strategy that is applied to all patients.

Formerly, patients with EBV-related disorders were mostly identified by qualitative PCR. However, since EBV DNA is present in a small fraction of lymphoid cells from every healthy virus carrier, quantitative methods are expected to be more reliable. Studies on EBV loads differ greatly depending on patient characteristics, the methods applied, the samples used for detection, and the methods by which the data are calculated. Different PCR techniques are used to quantify the viral load, including end point dilution PCR $(10,14,26)$, quantitative competitive PCR methods $(1,7,21,30,32)$, or real-time PCR detection $(12,23)$. Since PTLD in solid-organ transplant recipients differs from that in SCT recipients with regard to the source of EBV, the time of disease outbreak, and the course of the disease itself, SCT recipients should be grouped and ana- 
TABLE 1. Patient characteristics and transplantation procedure in patients with PTLD $^{a}$

\begin{tabular}{|c|c|c|c|c|c|c|}
\hline $\begin{array}{l}\text { Patient } \\
\text { no. }\end{array}$ & $\begin{array}{l}\text { Age } \\
(\mathrm{yr})\end{array}$ & Disease & Donor & Immunosuppression & $\begin{array}{l}\text { Day of } \\
\text { engraftment }\end{array}$ & $\begin{array}{l}\text { Antiviral treatment for prophylaxis or } \\
\text { preemptive CMV therapy }\end{array}$ \\
\hline 1 & 26 & SAA & MUD & ATG, CsA, MMF, prednisolone & 17 & days $0-30 \mathrm{ACV}$; from day $25, \mathrm{FC}, \mathrm{GCV}, \mathrm{GCV}+\mathrm{FC}$ \\
\hline 2 & 40 & MDS & MFD & TGM, CsA & 9 & days $0-30 \mathrm{ACV}$; from day $30, \mathrm{GCV}, \mathrm{GCV}+\mathrm{FC}$ \\
\hline 3 & 48 & CML & 2AgMM-FD ${ }^{b}$ & None & 14 & days $0-30 \mathrm{ACV}$; from day $14, \mathrm{FC}, \mathrm{GCV}, \mathrm{GCV}+\mathrm{FC}$ \\
\hline 4 & 34 & ALL & MÜD & ATG, CsA, MMF, prednisolone & 12 & days $0-30 \mathrm{ACV}$; from day $52, \mathrm{FC}, \mathrm{FC}+\mathrm{GCV}$, cidofovir \\
\hline 5 & 24 & ALL & MUD & ATG, CsA & 11 & days $0-30 \mathrm{ACV}$ \\
\hline 6 & 31 & ALL & MUD & ATG, CsA, MMF, prednisolone & 11 & days $0-30 \mathrm{ACV}$, from day $34, \mathrm{GCV}, \mathrm{FC}$ \\
\hline 7 & 34 & AML & MUD & ATG, CsA, MMF, prednisolone & 11 & days $0-30 \mathrm{ACV}$ \\
\hline 8 & 37 & AML & 1AgMM-DU ${ }^{b}$ & ATG, CsA, OKT3 & $10^{c}$ & days $0-30 \mathrm{ACV}$ \\
\hline 9 & 54 & MM & MUD & ATG, CsA, OKT3 & 28 & days $0-30 \mathrm{ACV}$, from day $19, \mathrm{GCV}$ \\
\hline
\end{tabular}

${ }^{a}$ Abbreviations: SAA, severe aplastic anemia; MDS, myelodysplastic syndrome; CML, chronic myeloid leukemia; ALL, acute lymphoblastic leukemia; AML, acute myeloid leukemia; MM, multiple myeloma; MUD, matched unrelated donor; 2AgMM-FD, family donor with two antigen mismatches; 1 AgMM-DU, unrelated donor with one antigen mismatch; ATG, antithymocyte globulin; CsA, cyclosporine; MMF, mycofenolate mofetil; ACV, acyclovir; FC, foscarnet; GCV, ganciclovir.

${ }^{b}$ Both patients received T-cell-depleted grafts.

${ }^{c}$ Primary graft failure with a second graft at day 34; engraftment was at day 10 after the second transplantation.

lyzed separately. So far only a few patients with SCT have been examined $(10,17,23,27)$.

The aim of the present study was to evaluate the dynamics and prognostic value of EBV load determination in order to facilitate preemptive therapy for PTLD after SCT. Importantly, because of the sample size in the present study $(n=$ 419), a threshold value could be established for PTLD and evaluated according to its sensitivity and specificity as well as to its positive and negative predictive values. Thus, it should allow correct interpretation of the EBV load.

\section{MATERIALS AND METHODS}

Patients, transplant characteristics, and treatment. The EBV loads in peripheral blood samples from 59 patients (22 children [ages, 1 to 18 years] and 37 adults [ages, 19 to 58 years]) were assayed after allogeneic SCT. Blood samples were collected at least every 2 weeks during the stay in hospital and at least every 4 weeks afterwards. The transplant characteristics of the patients with PTLD are summarized in Table 1. Nine adults were diagnosed with PTLD by immunohistochemical staining for EBV latent membrane protein 1, in situ hybridization, and/or PCR of the malignant B-cell population. Disease was monoclonal in seven patients. For the remaining two patients with PTLD, no clonality analysis was performed. Clinically, patients with PTLD presented with fever (patients 1 to 8), lymphadenopathy (patients 1 to 6,8 , and 9), tonsillitis (patient 4), and malaise (patients 7 and 9). Two patients (patients 3 and 8) received T-cell-depleted grafts. Conditioning regimens varied depending on the underlying disease. One patient (patient 9) received a conditioning regimen at a reduced dose ("minitransplantation") with a single dose of 2 Gy of hyperfractionated total body irradiation, cyclophosphamide ( $20 \mathrm{mg} / \mathrm{kg}$ of body weight/day over 2 days), fludarabine $\left(30 \mathrm{mg} / \mathrm{m}^{2} /\right.$ day over 5 days), and antithymocyte globulin $(20 \mathrm{mg} / \mathrm{kg} /$ day over 5 days) prior to transplantation. All other patients (patients 1 to 8 ) received hyperfractionated total body irradiation at $12 \mathrm{~Gy}$ and cyclophosphamide at 60 $\mathrm{mg} / \mathrm{kg} /$ day over 2 days. In two patients (patients 1 and 8), thiotepa at $5 \mathrm{mg} / \mathrm{kg}$ was added, and in four patients (patients 3 to 6), etoposide at $10 \mathrm{mg} / \mathrm{kg}$ was added. In four patients (patients $1,4,6$, and 7) receiving a stem cell graft from matched unrelated donors an intensive (compared to the standard dose) immunosuppressive regimen, involving a combination of four drugs from a national multicenter trial was administered. These patients received cyclosporine (maintenance level, $200 \mu \mathrm{g} /$ liter $)$, mycophenolate mofetil $(1,000 \mathrm{mg} /$ day from day 1$)$, and prednisolone $(0.5 \mathrm{mg} / \mathrm{kg} /$ day on days 7 to $14 ; 1 \mathrm{mg} / \mathrm{kg} /$ day on days 15 to 28 , and then tapering off of the dose), as well as antithymocyte globulin $(3.5 \mathrm{mg} / \mathrm{kg} / \mathrm{day}$ from days -4 to -2$)$. All patients received prophylactic acyclovir orally $(1,600 \mathrm{mg} /$ day $)$ or intravenously (750 mg/day) until day 30 . All patients with a CMV-seropositive donor or recipient were monitored at least weekly for CMV DNA by wholeblood PCR $(5,6)$. In case of two consecutive positive samples, preemptive therapy was introduced with ganciclovir $(10 \mathrm{mg} / \mathrm{kg} /$ day), foscarnet (for induction, $120 \mathrm{mg} / \mathrm{kg} /$ day; for maintenance, $90 \mathrm{mg} / \mathrm{kg} /$ day), or cidofovir $(5 \mathrm{mg} / \mathrm{kg} /$ week).

Fifty patients had no clinical, laboratory, or radiological signs of either overt or pending PTLD after SCT during the study period and follow-up (6 to 12 months). The distinction between EBV primary infection and reactivation was made according to the presence of immunoglobulin $\mathrm{G}$ directed against the EBV capsid antigen pretransplantation.

Nontransplant controls. EDTA-treated whole-blood samples from 60 healthy blood donors were obtained from the blood bank of the University of Homburg/ Saar. All were positive for immunoglobulin G directed against EBV capsid antigens.

Samples and quantitative competitive PCR. DNA was extracted from $200 \mu \mathrm{l}$ of EDTA-treated whole blood with the QIAamp blood kit (Qiagen, Hilden, Germany), as described in the manufacturer's protocol. Plasmid pGem $3 Z 30$ (Promega, Madison, Wis.), which contains a part of the p23 sequence with a deletion of 30 bp (kindly provided by Fritz Schwarzmann, Regensburg, Germany), was used as the internal standard. The external primers were CAG CTC CAC GCA AAG TCA GAT TG and ATC AGA AAT TTG CAC TTT CTT TGC, and the internal primers were TTC TGT TAA GGC TGT TGA CAT GAG and TTG GGG TCG TTT GAT TCT CGT GG. Each 50- $\mu$ l PCR mixture contained $50 \mathrm{mM} \mathrm{KCl} ; 1.5 \mathrm{mM} \mathrm{MgCl}_{2} ; 10 \mathrm{mM}$ Tris- $\mathrm{HCl}$ (pH 9.0); $1.5 \mathrm{U}$ of Taq DNA polymerase (Pharmacia, Freiburg, Germany); $200 \mu \mathrm{M}$ each dGTP, dATP, dCTP, and dTTP (Roche, Mannheim, Germany); and $5 \mu \mathrm{M}$ each primer. For the external PCR, $2 \mu$ l of purified template DNA and $2 \mu$ of internal standard were added. For the internal PCR, $2 \mu$ from the external PCR was used. PCR conditions (external and internal) were as follows: $94^{\circ} \mathrm{C}$ for $3 \mathrm{~min} ; 30$ cycles of $94^{\circ} \mathrm{C}(30 \mathrm{~s}), 60^{\circ} \mathrm{C}(30 \mathrm{~s})$, and $72^{\circ} \mathrm{C}(1 \mathrm{~min})$; and finally, $72^{\circ} \mathrm{C}$ for $7 \mathrm{~min}$. The PCR products were identified in an ethidium bromide-stained $2.5 \%$ agarose gel (SeaKem; FMC BioProducts, Rockland, Maine). Detection of the internal standard was used as an inhibition control. To ensure the validity of the results, several precautions were taken to avoid false-positive results, as described previously (16). The DNA concentration in the preparation used for PCR was quantified with a spectrophotometer at an optical density of $260 \mathrm{~nm}$. Results were calculated as the number of EBV genome copies per microgram of cellular DNA. The sensitivity of the PCR was determined with serial 10 -fold dilutions of Namalwa cells containing $2 \mathrm{EBV}$ copies/cell in $10^{5} \mathrm{EBV}$-negative cells. A minimum of 10 Namalwa cells containing a total of 20 EBV copies in a background of $10^{5}$ negative cells was required to be detectable by this PCR assay (7).

Statistical analysis. Statistical analysis was done by the Mann-Whitney test and Kaplan-Meier survival curve analysis. Positive predictive values were calculated as follows: (prevalence $\times$ sensitivity $\times 100) /[($ prevalence $\times$ sensitivity $)+$ $(100-$ prevalence $) \times(100-$ specificity $)]$. Negative predictive values were calculated as follows: $[(100-$ prevalence $) \times$ specificity $\times 100] /[(100-$ prevalence $) \times$ specificity + prevalence $\times(100-$ sensitivity $)]$.

\section{RESULTS}

Quantitative competitive PCR in nontransplant controls. The EBV DNA load in peripheral blood was monitored by a quantitative competitive PCR with DNA extracted from whole blood of 60 nontransplant control individuals. The sensitivity of the PCR was determined to be $20 \mathrm{EBV}$ DNA copies $/ 10^{5}$ negative cells. In healthy EBV-infected individuals, the EBV DNA copy number ranges from 0.01 to 0.1 copies $/ 10^{5}$ cells (36). Accordingly, latent infections were not detectable by the 


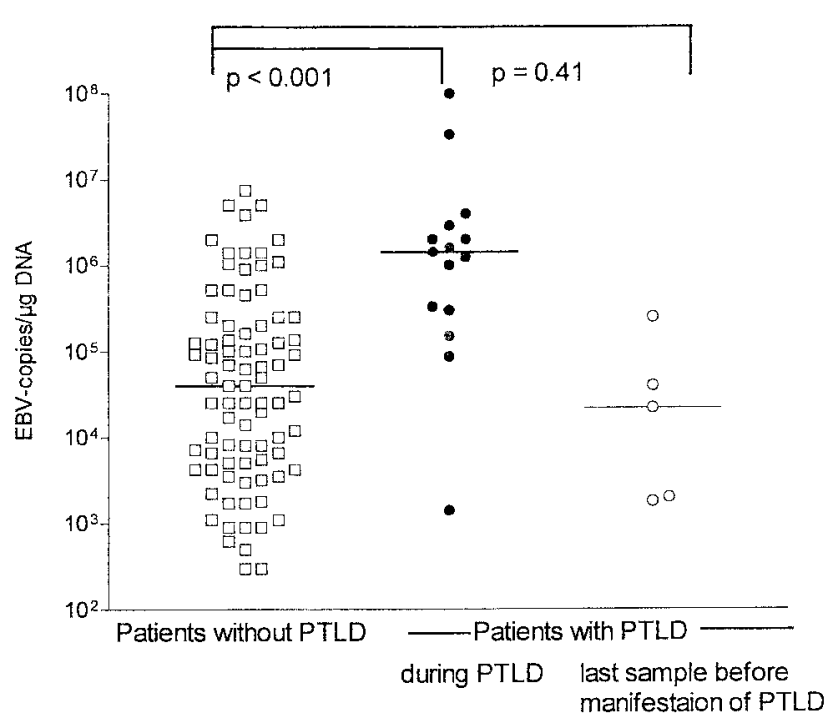

FIG. 1. Comparison of EBV loads in patients with and without PTLD. The EBV loads in EBV DNA-positive samples from patients without PTLD (open squares; median load, $4.0 \times 10^{4} \mathrm{copies} / \mu \mathrm{g}$ of DNA; 266 samples were negative) were compared with those in patients with PTLD at the time of diagnosis or during the course of PTLD (closed circles; median load, $1.4 \times 10^{6}$ copies/ $\mu$ g of DNA) and those in the last sample before PTLD was manifested (open circles; median load, $2.2 \times 10^{4}$ copies/ $\mu$ g of DNA; 1 sample was negative).

PCR used in the present study, and as expected, all 60 healthy blood donors tested negative by the PCR assay.

Sensitivity and specificity of use of EBV load for diagnosis of PTLD. The EBV loads were compared between patients with manifest PTLD at the time of diagnosis or during the course of PTLD (15 samples from nine patients [six patients with 2 samples each and three patients with one sample each]) and patients without any symptoms of PTLD (349 samples from 50 patients). Fifty-three samples that were obtained from patients who developed PTLD but that were taken before or after the manifestation of disease were not included in this analysis. All nine individuals experiencing PTLD had detectable levels of EBV at the time of clinical manifestation of PTLD and during the course of the disease. Among the 349 samples from 50 patients without any symptoms, EBV DNA was not detectable in 266 samples but was detectable in 83 samples. Figure 1 summarizes the EBV loads in these 83 EBV DNA-positive samples from patients without signs of PTLD (median load, $4 \times 10^{3}$ copies/ $\mu$ g of DNA; range, $3 \times 10^{2}$ to $7 \times 10^{6}$ ) copies/ $\mu \mathrm{g}$ of DNA) and the viral loads in patients with PTLD at the time of clinical manifestation of PTLD or during the course of disease (median load, $1.4 \times 10^{6}$ copies/ $\mu \mathrm{g}$ of DNA; range, $1.4 \times 10^{3}$ to $1 \times 10^{8}$ copies $/ \mu$ g of DNA $)(P<0.0001)$.

By using all 364 samples (349 samples from patients without PTLD and 15 samples from patients with PTLD obtained during the course of the disease), the sensitivities and specificities for different threshold values of EBV loads were calculated in order to define the best threshold value to distinguish patients with PTLD from patients without PTLD. Figure 2 shows the corresponding sensitivity and specificity for different threshold values of EBV DNA loads in the diagnosis of PTLD. A threshold value of $10^{5}$ copies/ $\mu$ g of DNA had the best diagnostic efficacy, with a sensitivity of $87 \%$ and a specificity of $91 \%$.
The positive and negative predictive values of a threshold value are influenced by the prevalence of PTLD. It has been shown that the prevalence of PTLD in patients undergoing SCT is $0.5 \%$ for patients without major risk factors and increases with the number of risk factors. For one, two, or three or more risk factors, the prevalences rise to $1.7,8$, and $22 \%$, respectively (3). By use of the threshold value of $10^{5}$ copies $/ \mu \mathrm{g}$ of DNA, this translates into a positive predictive value and a negative predictive value of 74 and $96 \%$, respectively, for patients with three or more risk factors. However, when only two major risk factors were present, the positive and negative predictive values are 46 and $98.7 \%$, respectively, and for patients with only one major risk factor, they are 14 and $99.7 \%$, respectively.

The development of PTLD relies on latent replication rather than lytic replication, and viral load does not discriminate between these two forms of replication. One might therefore suggest that antiviral drugs such as ganciclovir, foscarnet, cidofovir, or acyclovir that interfere with lytic replication but not latent replication may enhance the prognostic value of the EBV load since only genome copies from latent replication are detected. However, when the data were analyzed with regard to antiviral treatment, no significant effect on the viral load could be found (median for samples obtained while the patients were receiving antiviral treatment, 25,000 copies/ $\mu \mathrm{g}$ of DNA; median for samples obtained while the patients were not receiving treatment, 62,500 copies/ $\mu \mathrm{g}$ of DNA; $P=0.52$; data not shown). This supports the view that only a small percentage of cells support lytic replication of EBV.

Course after transplantation in patients with PTLD. PTLD occurred in 9 patients 25 to 170 days after SCT (median time, 55 days). No primary infection occurred in patients since all patients were infected with EBV prior to transplantation. All but one of the patients died within 2 to 22 days (median, 9 days) after the manifestation of PTLD due to rapidly progressive disease (Table 2; Fig. 3). In one patient (patient 3) the PTLD resolved completely and the EBV DNA load returned to negative 26 days after the first administration of unmanipulated donor T cells $\left(5 \times 10^{4} \mathrm{CD}^{+} \mathrm{T}\right.$ cells $\left./ \mathrm{kg}\right)$ and 12 days after the second administration.

In three patients (patients 2, 5, and 9) no samples were available prior to the clinical manifestation of PTLD; samples from the other six patients were assayed during the entire

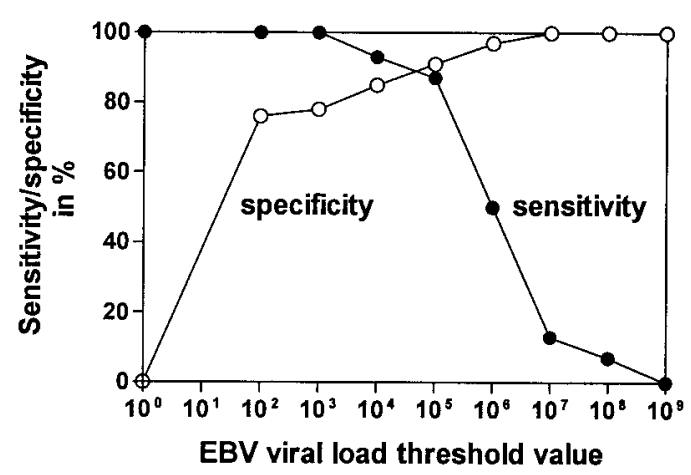

FIG. 2. Threshold value calculation for EBV load for diagnosis of PTLD. The corresponding sensitivities (closed symbols) and specificities (open symbols) for different threshold values are shown. 
TABLE 2. Onset, treatment, and outcome in patients with PTLD

\begin{tabular}{|c|c|c|c|}
\hline $\begin{array}{l}\text { Patient } \\
\text { no. }\end{array}$ & $\begin{array}{l}\text { Day of onset of } \\
\text { PTLD after SCT }\end{array}$ & $\begin{array}{c}\text { Treatment } \\
\text { (antiviral or antiproliferative agent) }\end{array}$ & Outcome \\
\hline 1 & 66 & Foscarnet + ganciclovir before onset of PTLD & Death on day 75 due to PTLD \\
\hline 2 & 44 & Foscarnet + ganciclovir before onset of PTLD & Death on day 52 due to PTLD \\
\hline 3 & 62 & Foscarnet before onset of PTLD, DLI ${ }^{a}$ (days 66 and 80 ) & $\begin{array}{l}\text { Complete resolution of lymphoma, death on day } 180 \\
\text { (aspergillosis) }\end{array}$ \\
\hline 4 & 170 & Cidofovir before onset of PTLD & Death on day 192 due to PTLD \\
\hline 5 & 54 & Cidofovir (from day 54), Rituximab ${ }^{b}$ at day 61 & Death on day 63 due to PTLD \\
\hline 6 & 117 & $\begin{array}{l}\text { Foscarnet + ganciclovir before onset of PTLD, DLI (day 120), } \\
\text { Rituximab (day 125) }\end{array}$ & Death on day 134 due to PTLD \\
\hline 7 & 55 & & Death on day 77 due to PTLD \\
\hline 8 & $38^{c}$ & Rituximab (day 43 after second graft) & Death on day 44 after second graft due to PTLD \\
\hline 9 & 25 & Ganciclovir before onset of PTLD, Rituximab (day 32) & Death on day 33 due to PTLD \\
\hline
\end{tabular}

${ }^{a}$ DLI, donor lymphocyte infusion.

${ }^{b}$ Rituximab, anti-CD20 antibody.

${ }^{c}$ After the second graft.

course of transplantation. In four of the six patients, the median time to the time of first detection of EBV DNA prior to the clinical onset of PTLD was 36 days (range, 20 to 71 days). In the remaining two patients, no conversion prior to PTLD was detected. In one patient (patient 1), EBV DNA was detectable at a low copy number a few days before transplantation and failed to return to negative during the entire course. In the other patient (patient 6), EBV DNA was detectable for the first time when PTLD was already manifest, but the viral load was low $\left(1.4 \times 10^{3}\right.$ copies/ $\mu$ g of DNA $)$. The median time at which EBV DNA was detectable for the first time after transplantation was 52 days (range, 16 to 121 days). In all but one patient (patient 6) a rapid 3- to 6-log increase in viral load was found 3 to 8 weeks after transplantation.

To predict PTLD, the EBV load prior to the onset of PTLD is of interest (Fig. 1). In one patient (patient 6; Fig. 3) all samples obtained prior to PTLD were EBV DNA negative. In the other five patients the viral loads in the last sample obtained prior to the onset of disease were not different from those in patients without PTLD (median load, $2.2 \times 10^{4}$ copies/ $\mu \mathrm{g}$ of DNA; range, $1.8 \times 10^{3}$ to $2.5 \times 10^{5} \mathrm{copies} / \mu \mathrm{g}$ of DNA; $P=0.41$ [not significant]).

Treatment for PTLD included anti-CD20 antibodies (Rituximab) in four patients (patients 5, 6, 8, and 9) 2 to 8 days after PTLD became manifest. It was not successful at this late stage of PTLD (Fig. 3, Table 2). In addition, donor lymphocyte infusions were available for two patients and were successful for one patient (patient 3). Patient 3 showed complete remission of lymphoma as well as clearance of EBV DNA from the blood. The other patient (patient 6) received a donor lymphocyte infusion 3 days after PTLD became clinically manifest, yet it was without success at this late stage of disseminated PTLD. Antiviral substances such as ganciclovir and/or foscarnet or cidofovir were administered as preemptive therapy for CMV primary infection or reactivation (patients 1 to $4,6,9$ ) or to treat clinically manifest PTLD (patient 5). Furthermore, all patients received aciclovir for 1 month after transplantation as prophylactic treatment. Six patients developed PTLD while they were under ganciclovir and/or foscarnet therapy (Table 1). Three patients did not receive anti-CMV treatment prior to PTLD since the donor and the recipient were CMV seronegative (patients 7 and 8) or did not develop CMV reactivation (patient 5). This observation of the development of PTLD while under antiviral prophylaxis is limited by the important fact that the present study was not designed as a systematical trial on whether antiviral drugs prevent PTLD.

Course after transplantation in patients without PTLD. EBV DNA was not detectable in any sample from 33 of 50 patients without PTLD. In the remaining 17 patients ( 8 children and 9 adults), 4 primary infections and 13 reactivations were detected (Fig. 4).

All primary infections occurred in children. EBV DNA was detected for the first time in peripheral blood samples 16 to 67 days (median, 33 days) after transplantation. EBV primary infection was asymptomatic in one patient but became clinically manifest as infectious mononucleosis with fever and hepatosplenomegaly in the other three patients. In addition, in one patient an exanthema developed after administration of antibiotics, as is typical for EBV primary infection. Primary infection was clinically self-limiting in all three patients, and EBV DNA was detectable for less than 7, 14, and 22 days, respectively. EBV DNA was detectable in one patient for more than 80 days, despite the resolution of all symptoms. Median peak levels during primary infections were $6.8 \times 10^{4}$ copies/ $\mu \mathrm{g}$ of DNA (range, $8 \times 10^{3}$ to $4.5 \times 10^{5}$ copies/ $\mu$ g of DNA) (Fig. 5).

In 13 patients, EBV reactivated after transplantation. In eight patients, blood samples were first positive for EBV DNA 35 to 121 days (median, 79 days) after transplantation. In the other five patients, the first blood samples taken were positive for EBV DNA; thus, the time of conversion could not be determined. The median peak EBV load in patients with reactivated infections was $6.6 \times 10^{4}$ copies/ $\mu \mathrm{g}$ of DNA (range, $5 \times 10^{2}$ to $7.4 \times 10^{6}$ copies/ $\mu$ g of DNA) and was thus comparable to that in patients with primary infections $(P=0.49$ [not significant]) (Fig. 5). EBV reactivations differed from EBV primary infections only by the time at which EBV replication was first detected in peripheral blood samples. Primary infections appeared significantly earlier (median, 33 days) than reactivated infections in patients without PTLD (median, 79 days) $(P=0.01)$ (Fig. 6B).

In a few patients without PTLD, the EBV load took a course similar to that in patients with PTLD. The typical rapid 3- to 6-log increase in virus titers at 3 to 18 weeks after transplantation was observed (Fig. 4). Patients with PTLD differed from patients without PTLD only in EBV load and not in the time 
A
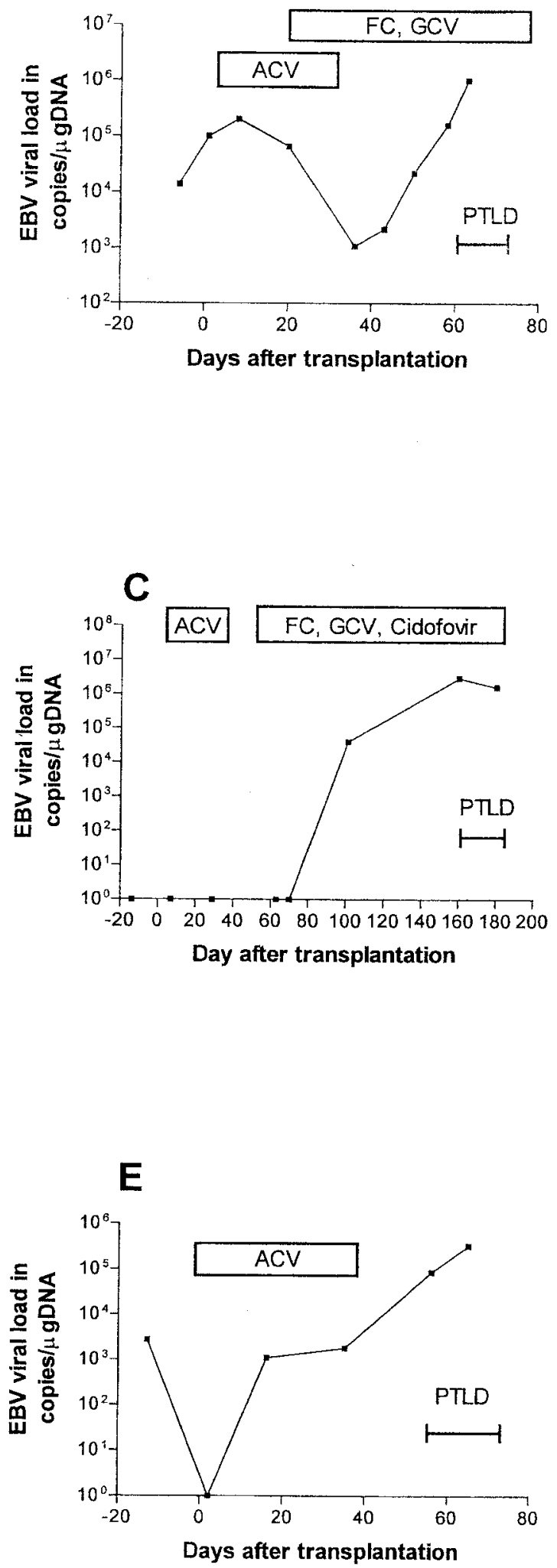

B

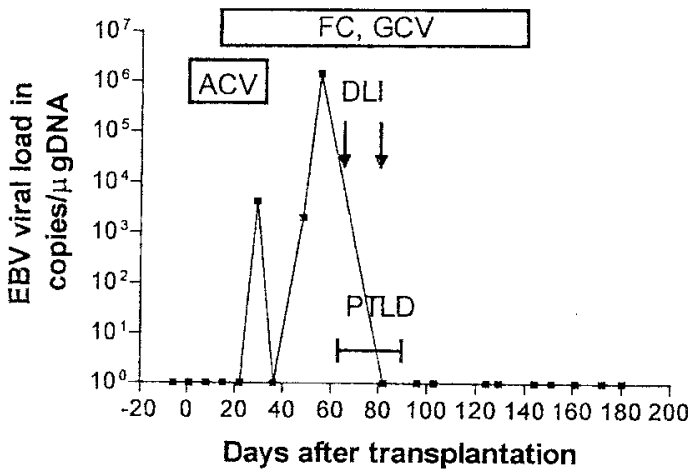

D
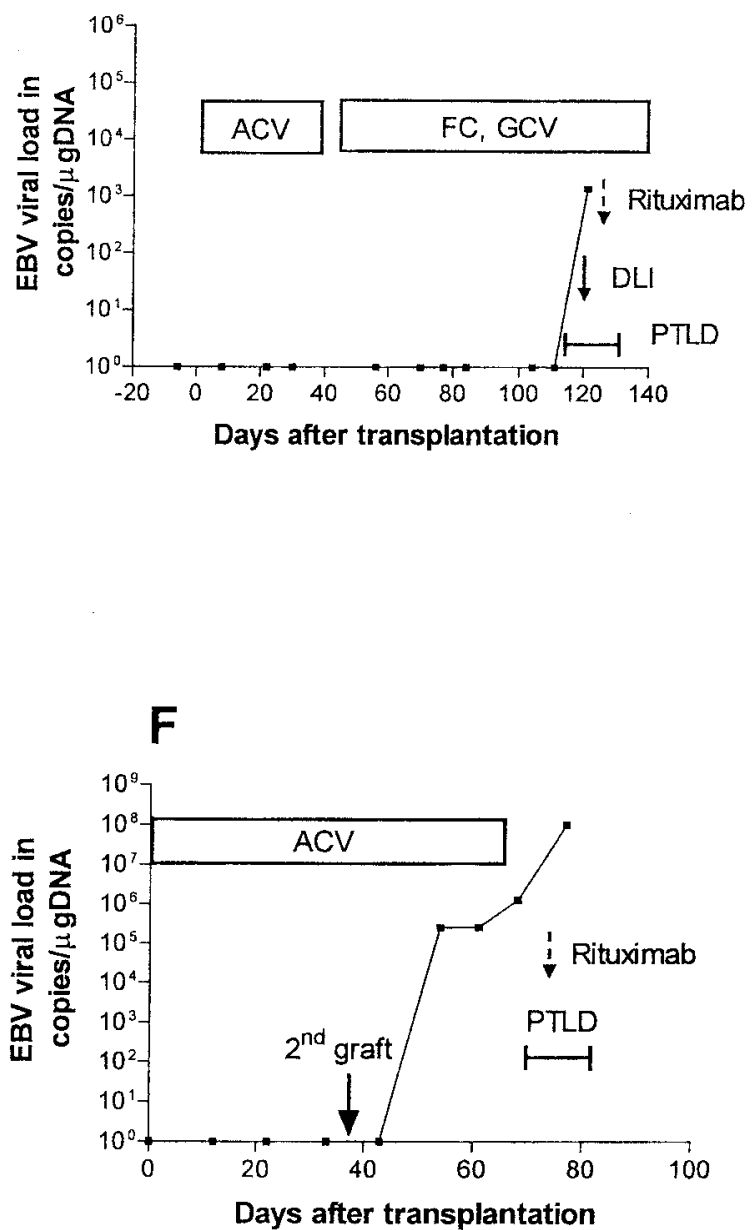

FIG. 3. EBV loads in patients developing PTLD after SCT. All patients received acyclovir (ACV) prophylaxis until day 30 after SCT. (A) Patient 1 developed high-grade B-cell non-Hodgkin's lymphoma during ganciclovir (GCV) and foscarnet (FC) treatment and received no further PTLD treatment. (B) Patient 3 developed diffuse large-cell B-cell non-Hodgkin's lymphoma during ganciclovir and foscarnet treatment; PTLD regressed after two donor lymphocyte infusions (DLI; solid arrows). (C) Patient 4 developed high-grade B-cell non-Hodgkin's lymphoma during antiviral treatment and received no further PTLD treatment. (D) Patient 6 developed high-grade B-cell non-Hodgkin's lymphoma during foscarnet, ganciclovir, and cidofovir treatment and additionally received donor lymphocyte infusions (solid arrow) and anti-CD20 antibody (Rituximab; dotted arrow). (E) Patient 7 received only acyclovir prophylaxis. (F) Patient 8 developed PTLD after a second transplantation due to primary graft failure. Acyclovir prophylaxis was extended until day 30 after the second transplantation. The patient received anti-CD20 antibody (Rituximab; dotted arrow). 


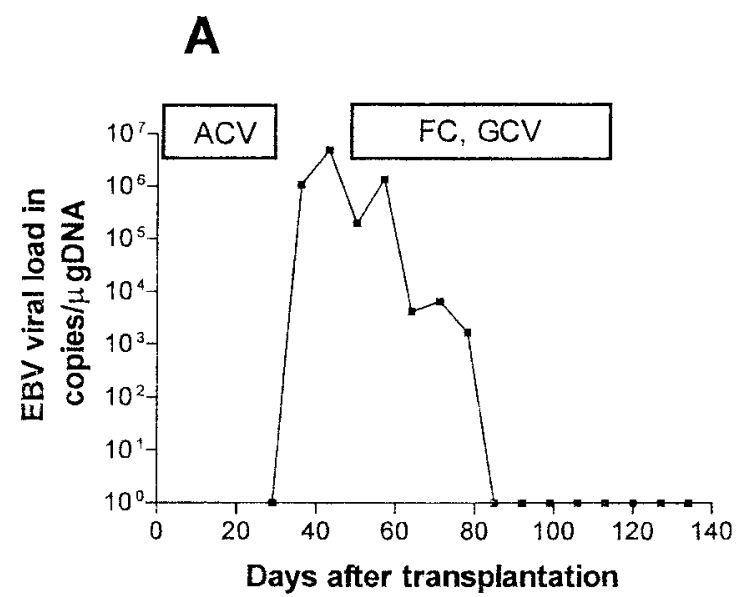

B

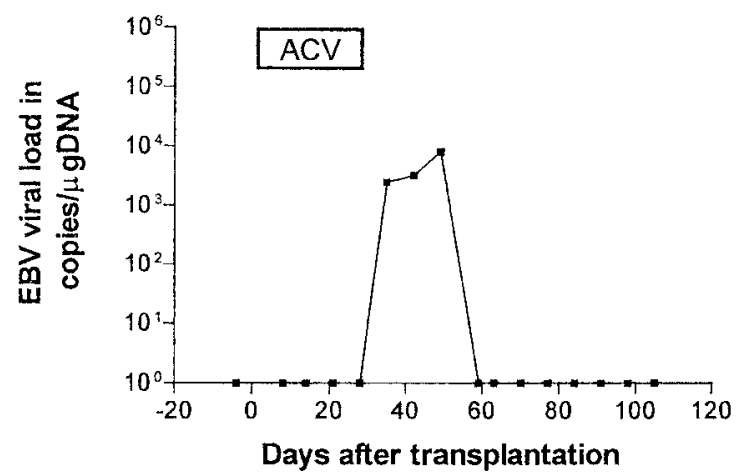

FIG. 4. Examples of EBV loads after SCT in patients who did not develop PTLD. (A) Adult patient with EBV reactivation without any EBV-related symptoms. (B) Pediatric patient with EBV primary infection and infectious mononucleosis. ACV, acyclovir; FC, foscarnet; GCV, ganciclovir.

when EBV replication was first detectable after transplantation (52 versus 63 days $P=0.91$ [not significant]) (Fig. 6A).

\section{DISCUSSION}

EBV-related PTLD usually occurs in a small percentage of patients with allogeneic SCT, with the highest frequency of occurrence being at 2 to 3 months after transplantation (3). The aim of the present study was to evaluate EBV load as a parameter for the prediction and monitoring of PTLD in such patients and to establish a threshold value. Disease developed in 9 of 59 patients. All nine patients shared several major risk factors known to be associated with PTLD.

The EBV load was analyzed by a quantitative competitive PCR with whole blood adjusted to a sufficiently low sensitivity to exclude positive results because of latently infected B-cell pools. The viral loads in patients with PTLD were compared with the viral loads in patients without PTLD. EBV DNA was detected in 26 of 59 individuals, indicating primary infection (in 4 patients) or reactivation. The EBV load was significantly elevated in patients with established PTLD compared to the loads in those without PTLD. Interestingly, the delay in EBV

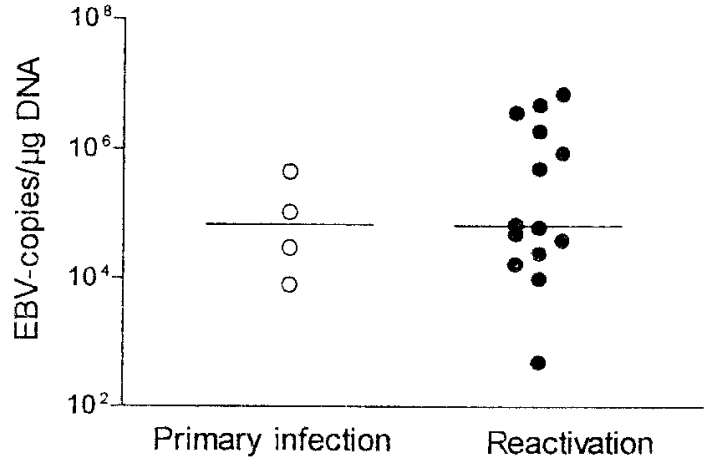

FIG. 5. Comparison of peak EBV load in patients with primary infection and reactivation. Open symbols, EBV primary infection (median load, $6.8 \times 10^{4}$ copies $/ \mu \mathrm{g}$ of DNA), closed symbols, EBV reactivation (median load, $6.6 \times 10^{4}$ copies $/ \mu$ g of DNA) $(P$ was not significant).

DNA replication after transplantation was the same in both groups. In contrast, when patients without PTLD were subdivided into those with primary infections and those with reactivations, an earlier onset of EBV replication was found in patients with primary infections. However, the peak viral loads during EBV replicative episodes were similar in both groups.

The early onset of EBV replication in patients with primary
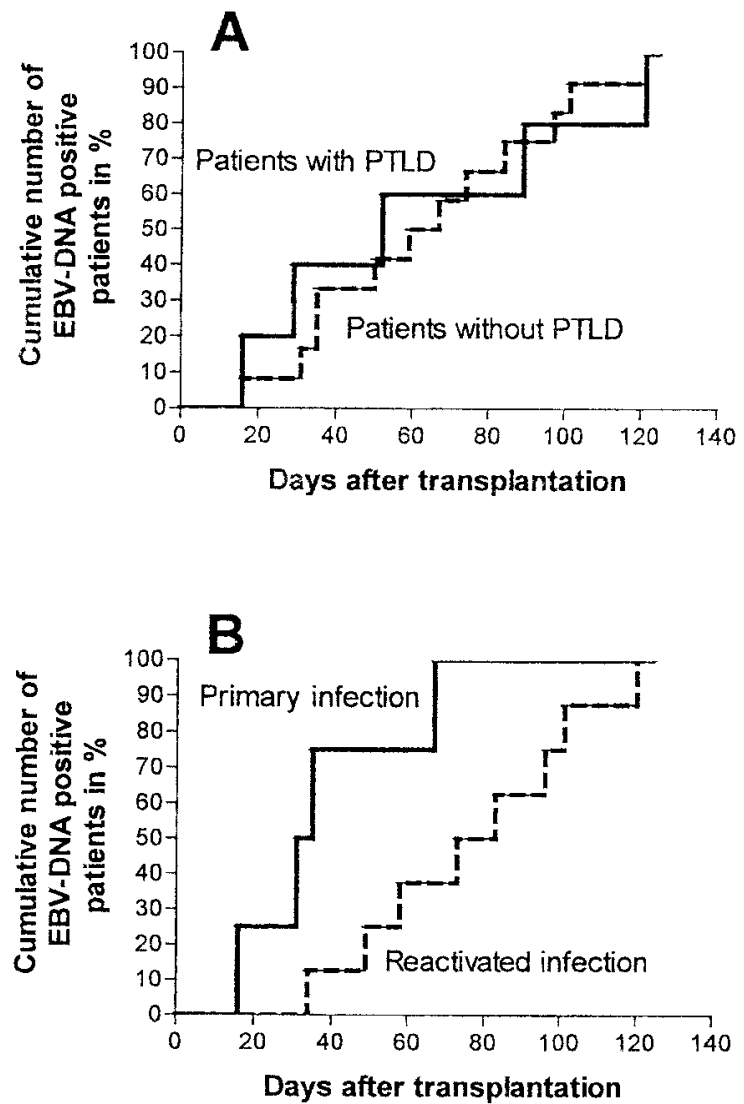

FIG. 6. First times of detection of EBV DNA-positive sample after transplantation. (A) First times of EBV DNA detection in patients with (solid line) and without PTLD (dotted line). (B) First times of EBV DNA-positive sample in patients with primary infection (solid line) or reactivation (dotted line). 
infection likely reflects the lack of a functional, previously established EBV-specific immune response. In contrast, in patients with a previously acquired EBV infection, the remaining recipient $\mathrm{T}$ cells may control EBV replication at an early stage even under posttransplantation immunosuppression or the process of reactivation may delay the start of replication. However, the peak viral loads eventually measured in individuals with primary infection and reactivation are similar, indicating that the primary and secondary immune responses possess comparable capacities to control EBV-infected cells and that a previously established immune response merely delays rather than inhibits DNA replication.

In the subgroup of patients with EBV replication that progressed to PTLD, viral replication was not effectively controlled and therefore resulted in a rapid increase in viral load and high peak titers. This may reflect a relative impairment of cytotoxic T-cell function in these patients. It thus seems that the EBV load can constitute a surrogate marker for circulating EBV-specific T cells and may be able to predict the development and regression of PTLD, at least in the majority of patients.

The EBV load as an indicator for an EBV-associated disease parallels some aspects of CMV disease. CMV disease is associated with a high viral load, yet patients with high viral loads do not necessarily develop CMV disease. As shown for EBV in the present study, only a minority of patients positive by PCR developed EBV-related symptomatic disease. Even among patients with primary infection, only three of four patients experienced infectious mononucleosis. Moreover, some patients with very high viral loads failed to develop PTLD, a phenomenon that has also been observed by others in individual patients $(8,14,21,26,28,30)$. It is tempting to speculate that these patients have sufficient EBV-specific cellular immune responses to keep EBV replication in check. Indeed, we recently showed for CMV that CMV DNA-positive transplant recipients may control replication depending on the presence of sufficient amounts of functional CMV-specific T cells. Thus, determination of the CMV load in combination with the CMV-specific T-cell immune response can significantly improve risk assessments for these patients (31). Similarly, use of that combination of methods may be as useful in EBV diagnostics to improve the prognostic value of testing.

In contrast to CMV disease, however, in which a negative viral load excludes disease, a negative or low EBV load does not strictly exclude the development of PTLD, as seen in individual patients in this and in other studies $(17,26,27,30,33)$. We have shown in one patient (patient 6) that the patient did not become positive for EBV DNA before the clinical manifestation of PTLD. Moreover, the viral load remained low in this patient. In spite of this and in spite of intensive therapy, the clinical course was rapidly progressive and the patient died 17 days after the disease became apparent. These and other findings indicate that the role of EBV in inducing and maintaining EBV-associated PTLD is ambiguous. This is underscored by a subgroup of B-lymphoblastoid cell lines expanded from EBV-positive PTLD lesions that were negative for EBV DNA in vitro (13). In conclusion, the predictive value of EBV load determination is limited by the pathogenic role of EBV in PTLD.

We established a threshold value for the EBV DNA load for the diagnosis of PTLD of $10^{5}$ copies/ $\mu$ g of DNA, which resulted in a sensitivity and a specificity of about $90 \%$ each. However, in transplant recipients with less than three major risk factors, the positive predictive value of this threshold remains low. Thus, therapeutic strategies for early intervention based on viral load could result in the unnecessary treatment of a significant number of patients. In these patients the EBV load must be interpreted carefully, and determination of the viral load should be combined with other diagnostic methods to increase its predictive value.

Successful preemptive therapy requires a diagnostic tool that identifies a patient at risk at least several days prior to disease manifestation $(15,28)$. However, it may take weeks to produce a significant number of EBV-reactive donor lymphocytes, especially when one relies on an unrelated donor. Since in the present study all but one patient was positive for EBV DNA some weeks before the manifestation of PTLD, the viral load seems to meet the criteria for a sufficiently sensitive diagnostic tool that can be used to guide preemptive therapy. However, it should be noted that the progression of the EBV load and PTLD occurred rapidly; thus, monitoring of the EBV load should be performed frequently during the first months after transplantation. This is underscored by the fact that even in the last sample obtained prior to the manifestation of PTLD, the EBV load was similar to that in patients who did not progress to PTLD.

The adequacy of antiviral treatment for the prophylaxis of PTLD is questionable because EBV may not necessarily replicate in transformed cells. Furthermore, the EBV thymidine kinase, which phosphorylates and activates substances such as ganciclovir and aciclovir, is not always expressed in patients with PTLD (20). Evaluation of the benefit of antiviral treatment is further limited by the lack of large randomized studies. Some studies seem to indicate a benefit from treatment but rely on historical controls $(4,19)$, whereas others find antiviral treatment ineffective (9). Notably, in our study, six of nine patients developed PTLD, despite aggressive antiviral therapy. Furthermore, prophylactic treatment with acyclovir was not beneficial in these patients. The effects of prophylactically administered antiviral substances are certainly different, depending on whether patients have a primary or reactivated infection. Lytic EBV replication but not latent EBV infection involves the expression of viral early proteins that are the specific targets of antiviral drugs. Thus, the failure of antiviral therapy in the present study might be due to the fact that all patients with PTLD were infected with EBV prior to transplantation.

In conclusion, EBV replication occurs in a significant number of patients after STC, but only a subgroup of patients develops PTLD. The determination of EBV load by quantitative competitive PCR proved to be a valuable tool that could be used to guide preemptive therapy, but it has limitations. One must be aware, however, of individual patients who develop EBV-associated PTLD in the presence of low EBV loads and of the low positive predictive value of EBV load determination for patients without major risk factors. Additional monitoring of the EBV-specific T-cell response may further improve the ability to predict PTLD in transplant recipients. 


\section{REFERENCES}

1. Baldanti, F., P. Grossi, M. Furione, L. Simoncini, A. Sarasini, P. Comoli, R Maccario, R. Fiocchi, and G. Gerna. 2000. High levels of Epstein-Barr virus DNA in blood of solid-organ transplant recipients and their value in predicting posttransplant lymphoproliferative disorders. J. Clin. Microbiol. 38: $613-619$.

2. Craig, F. E., M. L. Gulley, and P. M. Banks. 1993. Posttransplantation lymphoproliferative disorders. Am. J. Clin. Pathol. 99:265-276.

3. Curtis, R. E., L. B. Travis, P. A. Rowlings, G. Socie, D. W. Kingma, P. M. Banks, E. S. Jaffe, G. E. Sale, M. M. Horowitz, R. P. Witherspoon, D. A. Shriner, D. J. Weisdorf, H. J. Kolb, K. M. Sullivan, K. A. Sobocinski, R. P. Gale, R. N. Hoover, J. F. Fraumeni, Jr., and H. J. Deeg. 1999. Risk of lymphoproliferative disorders after bone marrow transplantation: a multiinstitutional study. Blood 94:2208-2216.

4. Darenkov, I. A., M. A. Marcarelli, G. P. Basadonna, A. L. Friedman, K. M. Lorber, J. G. Howe, J. Crouch, M. J. Bia, A. S. Kliger, and M. I. Lorber. 1997. Reduced incidence of Epstein-Barr virus-associated posttransplant lymphoproliferative disorder using preemptive antiviral therapy. Transplantation 64:848-852.

5. Einsele, H., G. Ehninger, H. Hebart, K. M. Wittkowski, U. Schuler, G. Jahn, P. Mackes, M. Herter, T. Klingebiel, J. Loffler, et al. 1995. Polymerase chain reaction monitoring reduces the incidence of cytomegalovirus disease and the duration and side effects of antiviral therapy after bone marrow transplantation. Blood 86:2815-2820.

6. Einsele, H., G. Ehninger, M. Steidle, A. Vallbracht, M. Muller, H. Schmidt, J. G. Saal, H. D. Waller, and C. A. Muller. 1991. Polymerase chain reaction to evaluate antiviral therapy for cytomegalovirus disease. Lancet 338:1170 112.

7. Gartner, B. C., K. Kortmann, M. Schafer, N. Mueller-Lantzsch, U. Sester, H. Kaul, and H. Pees. 2000. No correlation in Epstein-Barr virus reactivation between serological parameters and viral load. J. Clin. Microbiol. 38:2458.

8. Green, M., J. Bueno, D. Rowe, G. Mazariegos, L. Qu, K. Abu-Almagd, and J. Reyes. 2000. Predictive negative value of persistent low Epstein-Barr virus viral load after intestinal transplantation in children. Transplantation 70: 593-596.

9. Green, M., M. Kaufmann, J. Wilson, and J. Reyes. 1997. Comparison of intravenous ganciclovir followed by oral acyclovir with intravenous ganciclovir alone for prevention of cytomegalovirus and Epstein-Barr virus disease after liver transplantation in children. Clin. Infect. Dis. 25:1344-1349.

10. Gustafsson, A., V. Levitsky, J. Z. Zou, T. Frisan, T. Dallanis, P. Ljungman, O. Ringden, J. Winiarski, I. Ernberg, and M. G. Masucci. 2000. Epstein-Barr virus (EBV) load in bone marrow transplant recipients at risk to develop posttransplant lymphoproliferative disease: prophylactic infusion of EBVspecific cytotoxic T cells. Blood 95:807-814.

11. Heslop, H. E., C. Y. Ng, C. Li, C. A. Smith, S. K. Loftin, R. A. Krance, M. K. Brenner, and C. M. Rooney. 1996. Long-term restoration of immunity against Epstein-Barr virus infection by adoptive transfer of gene-modified virus-specific T lymphocytes. Nat. Med. 2:551-555.

12. Hoshino, Y., H. Kimura, K. Kuzushima, T. Tsurumi, K. Nemoto, A. Kikuta, Y. Nishiyama, S. Kojima, T. Matsuyama, and T. Morishima. 2000. Early intervention in post-transplant lymphoproliferative disorders based on Epstein-Barr viral load. Bone Marrow Transplant. 26:199-201.

13. Katz, B. Z., and U. Saini. 1992. Presence of the diffuse early antigen of Epstein-Barr virus in lymphomas and lymphoproliferative disorders. Am. J. Pathol. 140:1247-1254.

14. Kenagy, D. N., Y. Schlesinger, K. Weck, J. H. Ritter, M. M. GaudreaultKeener, and G. A. Storch. 1995. Epstein-Barr virus DNA in peripheral blood leukocytes of patients with posttransplant lymphoproliferative disease. Transplantation 60:547-554.

15. Kuehnle, I., M. H. Huls, Z. Liu, M. Semmelmann, R. A. Krance, M. K. Brenner, C. M. Rooney, and H. E. Heslop. 2000. CD20 monoclonal antibody (Rituximab) for therapy of Epstein-Barr virus lymphoma after hemopoietic stem-cell transplantation. Blood 95:1502-1505.

16. Kwok, S., and R. Higuchi. 1989. Avoiding false positives with PCR. Nature 339:237-238.

17. Lucas, K. G., R. L. Burton, S. E. Zimmerman, J. Wang, K. G. Cornetta, K. A Robertson, C. H. Lee, and D. J. Emanuel. 1998. Semiquantitative EpsteinBarr virus (EBV) polymerase chain reaction for the determination of patients at risk for EBV-induced lymphoproliferative disease after stem cell transplantation. Blood 91:3654-3661.

18. Manez, R., M. C. Breinig, P. Linden, J. Wilson, J. Torre-Cisneros, S. Kusne, S. Dummer, and M. Ho. 1997. Posttransplant lymphoproliferative disease in primary Epstein-Barr virus infection after liver transplantation: the role of cytomegalovirus disease. J. Infect. Dis. 176:1462-1467.

19. McDiarmid, S. V., S. Jordan, G. S. Kim, M. Toyoda, J. A. Goss, J. H. Vargas, M. G. Martin, R. Bahar, A. L. Maxfield, M. E. Ament, R. W. Busuttil, and G. S. Lee. 1998. Prevention and preemptive therapy of postransplant lym- phoproliferative disease in pediatric liver recipients. Transplantation 66: 1604-1611.

20. Mentzer, S. J., J. Fingeroth, J. J. Reilly, S. P. Perrine, and D. V. Faller. 1998 Arginine butyrate-induced susceptibility to ganciclovir in an Epstein-Barrvirus-associated lymphoma. Blood Cells Mol. Dis. 24:114-123.

21. Mutimer, D., N. Kaur, H. Tang, S. Singhal, J. Shaw, L. Whitehead, A Rickinson, and G. Niedobitek. 2000. Quantitation of Epstein-Barr virus DNA in the blood of adult liver transplant recipients. Transplantation 69: 954-959.

22. Nalesnik, M. A., R. Jaffe, T. E. Starzi, A. J. Demetris, K. Porter, J. A. Burnham, L. Makowka, M. Ho, and J. Locker. 1988. The pathology of posttransplant lymphoproliferative disorders occurring in the setting of cyclosporine A-prednisone immunosuppression. Am. J. Pathol. 133:173-192.

23. Niesters, H. G., J. van Esser, E. Fries, K. C. Wolthers, J. Cornelissen, and A. D. Osterhaus. 2000. Development of a real-time quantitative assay for detection of Epstein- Barr virus. J. Clin. Microbiol. 38:712-715.

24. Orazi, A., R. A. Hromas, R. S. Neiman, T. C. Greiner, C. H. Lee, L. Rubin, S. Haskins, N. A. Heerema, V. Gharpure, R. Abonour, E. F. Srour, and K. Cornetta. 1997. Posttransplantation lymphoproliferative disorders in bone marrow transplant recipients are aggressive diseases with a high incidence of adverse histologic and immunobiologic features. Am. J. Clin. Pathol. 107: 419-429.

25. Paya, C. V., J. J. Fung, M. A. Nalesnik, E. Kieff, M. Green, G. Gores, T. M. Habermann, P. H. Wiesner, J. L. Swinnen, E. S. Woodle, and J. S. Bromberg. 1999. Epstein-Barr virus-induced posttransplant lymphoproliferative disorders. ASTS/ASTP EBV-PTLD Task Force and The Mayo Clinic Organized International Consensus Development Meeting. Transplantation 68:15171525.

26. Riddler, S. A., M. C. Breinig, and J. L. McKnight. 1994. Increased levels of circulating Epstein-Barr virus (EBV)-infected lymphocytes and decreased EBV nuclear antigen antibody responses are associated with the development of posttransplant lymphoproliferative disease in solid-organ transplant recipients. Blood 84:972-984

27. Rooney, C. M., S. K. Loftin, M. S. Holladay, M. K. Brenner, R. A. Krance, and H. E. Heslop. 1995. Early identification of Epstein-Barr virus-associated post-transplantation lymphoproliferative disease. Br. J. Haematol. 89:98103

28. Rooney, C. M., C. A. Smith, C. Y. Ng, S. Loftin, C. Li, R. A. Krance, M. K. Brenner, and H. E. Heslop. 1995. Use of gene-modified virus-specific T lymphocytes to control Epstein-Barr-virus-related lymphoproliferation. Lancet 345:9-13.

29. Rooney, C. M., C. A. Smith, C. Y. Ng, S. K. Loftin, J. W. Sixbey, Y. Gan, D. K. Srivastava, L. C. Bowman, R. A. Krance, M. K. Brenner, and H. E. Heslop. 1998. Infusion of cytotoxic $\mathrm{T}$ cells for the prevention and treatment of Epstein-Barr virus-induced lymphoma in allogeneic transplant recipients. Blood 92:1549-1555.

30. Rowe, D. T., L. Qu, J. Reyes, N. Jabbour, E. Yunis, P. Putnam, S. Todo, and M. Green. 1997. Use of quantitative competitive PCR to measure EpsteinBarr virus genome load in the peripheral blood of pediatric transplant patients with lymphoproliferative disorders. J. Clin. Microbiol. 35:16121615.

31. Sester, M., U. Sester, B. Gartner, G. Heine, M. Girndt, N. Mueller-Lantzsch, A. Meyerhans, and H. Kohler. 2001. Levels of virus-specific CD4 T cells correlate with cytomegalovirus control and predict virus-induced disease after renal transplantation. Transplantation 71:1287-1294.

32. Stevens, S. J., I. Pronk, and J. M. Middeldorp. 2001. Toward standardization of Epstein-Barr virus DNA load monitoring: unfractionated whole blood as preferred clinical specimen. J. Clin. Microbiol. 39:1211-1216.

33. Stevens, S. J., E. A. Verschuuren, I. Pronk, W. van der Bij, M. C. Harmsen, T. H. The, C. J. Meijer, A. J. van den Brule, and J. M. Middeldorp. 2001. Frequent monitoring of Epstein-Barr virus DNA load in unfractionated whole blood is essential for early detection of posttransplant lymphoproliferative disease in high-risk patients. Blood 97:1165-1171.

34. Swinnen, L. J., G. M. Mullen, T. J. Carr, M. R. Costanzo, and R. I. Fisher. 1995. Aggressive treatment for postcardiac transplant lymphoproliferation. Blood 86:3333-3340.

35. Thorley-Lawson, D. A. 1989. Immunological responses to Epstein-Barr virus infection and the pathogenesis of EBV-induced diseases. Biochim. Biophys. Acta 948:263-286.

36. Wagner, H. J., G. Bein, A. Bitsch, and H. Kirchner. 1992. Detection and quantification of latently infected B lymphocytes in Epstein-Barr virus-seropositive, healthy individuals by polymerase chain reaction. J. Clin. Microbiol. 30:2826-2829.

37. Walker, R. C., W. F. Marshall, J. G. Strickler, R. H. Wiesner, J. A. Velosa, T. M. Habermann, C. G. McGregor, and C. V. Paya. 1995. Pretransplantation assessment of the risk of lymphoproliferative disorder. Clin. Infect. Dis. 20:1346-1353. 